\title{
Marxismo-leninismo, pensamiento iconoclasta y nuevo sentido común socialista en Chile durante la década de $1980 .{ }^{1}$
}

\author{
Marxism-leninism, iconoclastic thinking and socialist new common \\ sense in Chile during the 1980s.
}

\author{
Marcelo Mella Polanco ${ }^{2}$
}

\begin{abstract}
Resumen
Este artículo analiza el proceso de reconstrucción de los repertorios ideológicos y estratégicos en el socialismo chileno después de la caída del gobierno del presidente Allende y su coalición de partidos, la Unidad Popular. Particularmente, se abordarán los desplazamientos ideológicos de la izquierda en el contexto del proceso de la "renovación socialista". Al mismo tiempo, indagaremos en las vinculaciones entre teorías "iconoclastas" como el "marxismo analítico" y la reconstrucción del socialismo durante la década de 1980, en el contexto de la consolidación de la oposición moderada al régimen autoritario de Pinochet. Se sostiene en este trabajo que la crítica al marxismo leninismo desarrollada por la "renovación socialista" constituyó una forma de interiorización frente a la experiencia de la derrota del proyecto de la Unidad Popular y el aniquilamiento posterior. En este transcurso, la apropiación de diferentes expresiones de pensamiento "iconoclasta" permitió reconstruir un nuevo sentido común para el socialismo con alta propensión adaptativa frente a las condiciones históricas preexistentes.

Palabras claves: Renovación socialista, pensamiento izquierda, política chilena, marxismo leninismo, transición política.
\end{abstract}

\begin{abstract}
Abstact
This article analyzes the process of reconstruction of the ideological and strategic repertoires in the Chilean socialism after the fall of President Allende and his coalition of parties, the Unidad Popular. Particularly, will be examined the ideological displacements of the left in the context of the process of "renovación socialista". At the same time, will investigate the linkages between "iconoclastic" theories as "analytical marxism" and reconstruction of socialism during the 1980s, in the context of the consolidation of the moderate opposition to the authoritarian regime of Pinochet. It is

\footnotetext{
1 Este artículo ha sido elaborado en el marco de los proyectos "Coaliciones gubernamentales en regímenes presidenciales: análisis de los mecanismos de formación, mantenimiento y disolución en los casos de Uruguay, Argentina y Chile (1983 a 2010)" financiado por DICYT, Universidad de Santiago de Chile, código 031152MP y "Contexto histórico y dinámicas políticas de la insurgencia armada en Chile (1978-1994)" financiado por FONDECYT Regular, código 1130323.

${ }^{2}$ Doctor en Estudios Americanos, IDEA-Universidad de Santiago de Chile. Magister en Ciencia Política, INAP-Universidad de Chile. Licenciado en Historia, Instituto de Historia, Universidad Católica de Valparaíso. Profesor Departamento de Historia. Universidad de Santiago de Chile. marcelo.mella@usach.cl
} 
argued in this paper that the critique of marxism-leninism developed by the "renovación socialista" constituted a form of internalization compared to the experience of the defeat of the Unidad Popular project and the subsequent political annihilation. In this course, the appropriation of different expressions of "iconoclastic" thought allows to reconstruct a new common sense for socialism with adaptive high propensity regarding preexisting historical conditions.

Keywords: Socialist renewal, left thinking, Chilean politics, Marxism-Leninism, political transition.

\begin{abstract}
Reconocer abiertamente los errores, poner al descubierto sus causas, analizar la situación que los ha engendrado y discutir atentamente los medios de corregirlos: eso es lo que caracteriza a un partido serio; en eso consiste el cumplimiento de sus deberes V. I. Lenin. La revolución proletaria y el renegado Kautsky
\end{abstract}

El artículo aborda el estudio de los factores de crisis del pensamiento marxista leninista en Chile durante el Régimen Autoritario de Pinochet, así como, los fundamentos que hicieron posible la reconstrucción ideológica de la "izquierda reformista" en las décadas de 1980 y 1990.

Aunque con anterioridad hemos analizado las implicancias ideológicas y conceptuales del "giro reformista" de la izquierda chilena, principalmente orientadas a la mejor comprensión del diseño del proceso transicional (Mella, 2011a); en esta oportunidad nos interesa comprender los fundamentos teóricos para el surgimiento de un nuevo "sentido común" en el socialismo concertacionista. En buena parte, la resiliencia del "pensamiento de izquierda después del golpe" (Paramio, 1986) estuvo condicionada por el distanciamiento de los proyectos históricos preexistentes a 1973 y su desplazamiento hacia antípodas ideológicas por la recepción de conceptos y autores "iconoclastas".

Si la fase de desarrollo ideológico en la izquierda socialista que va desde la Revolución Cubana en 1959 hasta el triunfo electoral de la Unidad Popular en 1970, se caracterizó como una etapa marcada por la radicalización estratégica del PS y por una creciente influencia de concepciones leninistas-revolucionarias; el período que va desde fines de la década de 1970 y 1990, constituyó un momento marcado por la recepción de la experiencia de la crisis del socialismo internacional y por el imperativo político estratégico de superar el Régimen Autoritario.

En este trabajo nos interesa indagar como (mediante que repertorios conceptuales y acomodos estratégicos) la tradición del pensamiento de izquierda de raigambre socialista en Chile se desplazó, en un lapso de una década, desde orientaciones marxistas-leninistas a una alineación con perspectivas iconoclastas, entre las que 
destaca el "marxismo de la elección racional", también denominado, "marxismo analítico" (Levine, Sober y Wright, 1987). Dicho paradigma, de matriz individualista y racionalista, constituyó un esfuerzo de adaptación al liberalismo y a los entornos culturales de las sociedades de mercado.

¿Cómo impactaron estos desplazamientos ideológicos a las definiciones estratégicas de la izquierda chilena y, específicamente, a la "renovación socialista"? ¿Cuál fue la relación entre las teorías iconoclastas (entre ellas, el "marxismo analítico") y los procesos adaptativos del pensamiento Concertacionista y del Socialismo en particular?

Tal como las tradiciones heterodoxas fueron relevantes en un primer momento para definir la orientación estratégica de la oposición reformista al autoritarismo en el proceso de transición (Mella, 2008); afirmamos que existió un segundo momento, en el que el pensamiento iconoclasta en la izquierda, y especialmente el "marxismo analítico", sentaron las bases ideológicas y estratégicas de los gobiernos concertacionistas de Patricio Aylwin (1990-1994), Eduardo Frei Ruiz-Tagle (19942000), Ricardo Lagos (2000-2006) y Michelle Bachelet (2006-2010) (Mella, 2010) (Mella, 2011a) (Mella, 2011b). Este segundo momento resultó ser decisivo, cuando el objetivo fue comprender la propensión a la inercia y al statu quo que caracterizó a la Concertación, coalición constituida originalmente con vocación progresista.

Nuestro supuesto ha sido que la crisis del pensamiento de izquierda en Chile no solo se expresó en los efectos de la represión autoritaria, o como derrumbe de un paradigma "preexistente", sino también, mediante la recepción (voluntaria o forzosa) de tradiciones nuevas surgidas en el contexto de los debates europeos en tiempos de crisis de la ortodoxia marxista (Moyano, 2011; Santoni, 2013). Esta mirada hace posible analizar el desplazamiento de las tradiciones anteriores, la conexión del pensamiento con la acción y los ajustes entre creencias y decisiones. De todas formas, suponemos que es necesario identificar los lazos entre las acciones y las tradiciones de pensamiento en uso, por cuanto, la elaboración de un soporte de pensamiento permite dar continuidad en el tiempo a las políticas (reduciendo los conflictos entre racionalidades sucesivas) y bajar los costos derivados de los desplazamientos ideológicos o estratégicos.

En relación al enfoque del estudio, se ha optado por utilizar una perspectiva de historia del pensamiento político, con el propósito de centrarnos en los repertorios de reemplazo, desplazamiento y ruptura en la tradición de la izquierda chilena durante las décadas de 1980 y 1990. Con J.G.A. Pocock (2009) entendemos que el pensamiento es un modo de relación de los sujetos con las instituciones sociales, lo que supone interiorización de la experiencia y ciertos grados de abstracción de conceptos provenientes de tradiciones particulares. Al mismo tiempo, supone que existen interacciones entre los sujetos y una tradición de pensamiento, mediante las cuales, se podría entender las rupturas ideológicas y los desarrollos de la subjetividad. Por tanto, nos interesa el pensamiento de la renovación socialista y la afluencia del marxismo de la elección racional 
(analítico) en las creencias de los actores; como fórmulas destinadas a equilibrar la experiencia en un mundo asumido como ajeno y la necesidad de actuar en contra de la violencia autoritaria.

\section{LA FUERZA DE LAS CIRCUNSTANCIAS}

La inclinación al orden, observada en la evolución del pensamiento socialista chileno desde fines de los años ochenta, desplazó a una concepción de la política como enfrentamiento y lucha, fundada en una racionalidad contra-adaptativa y proclive a la ruptura con el orden liberal capitalista. (Walker, 1990) Desde la década de 1990, la Concertación como coalición gubernamental y el socialismo como actor sobresaliente de dicho conglomerado, mantuvieron de manera persistente y sistemática, altos niveles de continuidad con el modelo heredado del autoritarismo, así como también, respecto de la orientación ideológica de sus políticas.

Los trabajos del democristiano Edgardo Boeninger (1998) (2007) sugieren que como primer factor de explicación de la modificación de las creencias en la izquierda reformista (PS, PPD, sectores MAPU y MIR) que se integró a la Concertación, es necesario considerar la experiencia del fracaso político y estratégico del proyecto de la Unidad Popular. (Boeninger, 1998) Esto lleva a concluir a Boeninger que el proceso de desarrollo político chileno muestra que en aquellos momentos en los cuales la clase política optó por lógicas de enfrentamiento, la totalidad del sistema se estancó o sufrió dinámicas involutivas. En cambio, en aquellos momentos en los que la interacción permitió la cooperación y el compromiso entre los actores políticos, el resultado fue el avance en el proceso de democratización. Para este enfoque, el fracaso del gobierno de la UP y el quiebre de la democracia en 1973 debería ser comprendido, sin descartar los factores de contexto internacional, como un fracaso estratégico de los partidos que integraron la coalición o apoyaron al gobierno del presidente Allende. (Boeninger, 1998)

En el siguiente cuadro (Cuadro 1) se muestra la evolución de los patrones de autoridad en Chile desde los inicios de la república hasta 2010, en base a los datos de Polity IV elaborado por el Center for Systemic Peace. La información se presenta en una escala tricotómica de 10 a -10, en la que el rango -10 a -6 corresponde a "Autocracia", el rango -5 a +5 corresponde a "Anocracia" (Regímenes híbridos) y el rango +6 a +10 a "Democracia". De acuerdo a estos parámetros, se puede apreciar que la regresión democrática (desdemocratización) más severa a lo largo de la historia republicana se produjo en la coyuntura de 1973 y abarca la totalidad del período autoritario de Pinochet.

Cuadro 1: Evolución patrones de autoridad en Chile 


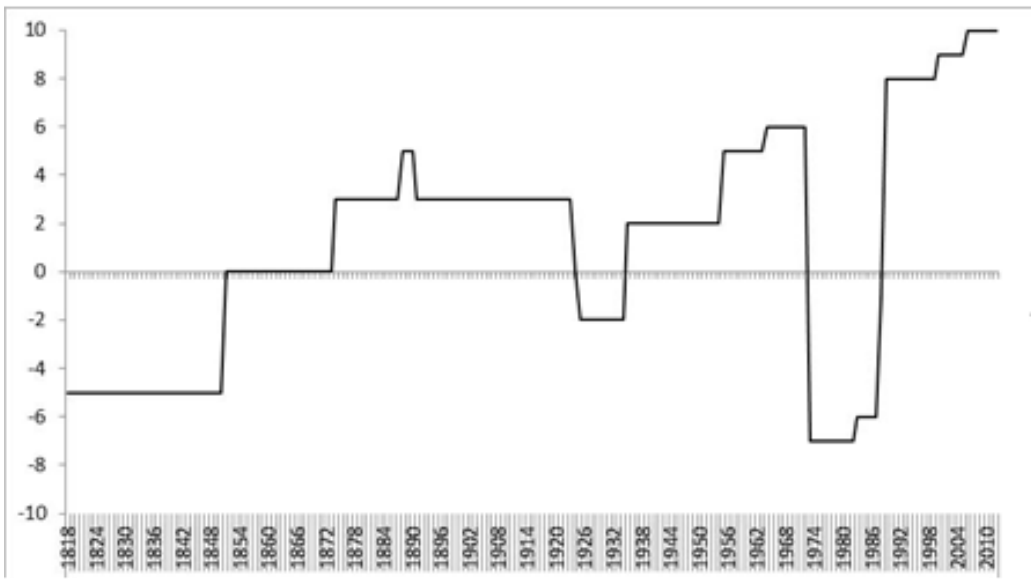

Fuente: Elaboración propia en base a datos de POLITY IV

El Informe de la Comisión de Verdad y Reconciliación (Informe Rettig) (1991) consigna, además de la proliferación de violaciones a los derechos humanos por parte del gobierno del general Pinochet, el profundo quiebre democrático acaecido que produce diversas modalidades de regresión institucional, entre estas:

a) A nivel de poderes públicos

- Disolución de Congreso y del Tribunal Constitucional (DL N²7)

- Proscripción y receso de partidos políticos (DL N 77 y 78)

- Caducidad e incineración de registros electorales (DL $\mathrm{N}^{\circ} 130$ )

- Cesación de Alcaldes y Regidores (DL N²5)

- Interinidad de la Administración Pública (DL N 6, DL N²2, DL N 98)

b) A nivel de garantías constitucionales

- Estados de Emergencia (DL N $\mathrm{N}^{\circ}$ 3, $\mathrm{DL} \mathrm{N}^{\circ}$ 4, DL N $\mathrm{N}^{\circ}$ 5, DL N $\mathrm{N}^{\circ}$ 922, $\mathrm{DL} \mathrm{N}^{\circ} 640$, $\mathrm{DL} \mathrm{N}^{\circ} 228, \mathrm{DL} \mathrm{N}^{\circ} 951$, DL $\left.\mathrm{N}^{\circ} 81\right)$

- Control de la actividad Sindical (DL $\left.\mathrm{N}^{\circ} 198\right)$

- Intervención de las Universidades. (DL N $\mathrm{N}^{\circ} 50, \mathrm{DL} \mathrm{N}^{\circ} 111, \mathrm{DL} \mathrm{N}^{\circ} 112, \mathrm{DL} \mathrm{N}^{\circ}$ 139)

Aunque después de 1989 se produjo la recuperación de la democracia y la superación del patrón "autocrático", no es menos cierto que la gobernabilidad del modelo chileno fue concomitante con una alta capacidad de adaptación de la izquierda concertacionista a las instituciones y estrategias de desarrollo implementadas por Pinochet. Por supuesto, esta propensión del socialismo a la estabilidad y el orden tiene afinidad con la experiencia extendida del fracaso de la UP, de la represión autoritaria que afectó a la izquierda y de la fragmentación del Partido Socialista, después del quiebre democrático en 1973 y durante la década de1980.

Observamos que desde la división del PS a finales de la década de 1970, entre PS Altamirano (1979), PS Almeyda (1981) y PS Coordinadora Nacional de Regiones (Vuskovic, 1977); le siguen durante los años 80 nuevos fraccionamientos, a saber, PS 
Comité Político de Unidad (1984), PS XXIV Congreso (1986), PS Núñez, PS Mandujano (ambos surgidos del Comité de Unidad de 1984), PS Unitario y PS Dirección Colectiva. A estos complejos procesos partidarios hay que agregar desde 1983 la incorporación de sectores del MAPU al proceso de renovación socialista y especialmente al PS Núñez. En este contexto fue el eje PS Altamirano, PS Comité de Unidad y posteriormente, PS Núñez, más los sectores del MAPU que se incorporan a esta tendencia quienes internalizan ciertas narrativas para hacer viable la estrategia pactista de transición y gobierno. (Walker, 1990)

Con todo, es necesario hacer presente que existieron en actores tales como el Partido Comunista, el MIR y el FPMR, otros procesos de reinterpretación de la experiencia del fracaso de "La Vía Chilena al Socialismo" que darán lugar a otras redefiniciones estratégicas, entre estas últimas, las perspectivas insurreccionales y la política de rebelión popular de masas. (Valdivia, Álvarez y Pinto, 2006: 101-206) Incluso dentro del socialismo es posible percibir las tensiones entre sectores proclives a la convergencia estratégica y sectores inclinados a definiciones estratégicas revolucionarias. A fines de los años 80 y frente a los posicionamientos generados por la inminencia del plebiscito de 1988, Adonis Sepúlveda señalaba:

"Sabemos que hay quienes sostienen que estas posiciones son añejas y no corresponden a la realidad actual; cuestionan su validez. Con esto no solo despojan al Partido de la base teórica para formular sus líneas estratégicas y tácticas, sino que lo dejan entregado al clásico empirismo oportunista. Quienes defendemos el pensamiento histórico del Partido y la vigencia teórica de sus postulados, sostenemos que el P.S. es una necesidad política y social en el país no por su pasado heroico sino porque sus ideas crearon perspectiva propia de poder en el pueblo de Chile. Esto no era voluntarismo ni exaltaciones pequeño burguesas sino la aplicación de concepciones afincadas en la teoría y práctica del marxismo y lo esencial del pensamiento de Lenin.” (Sepúlveda, 1988: 149)

\section{CONTINUIDAD Y PROFUNDIZACIÓN}

A nivel de acciones políticas, la propensión al status quo de la Concertación, como Gobierno de Coalición, fue especialmente notoria en dos aspectos: i) la continuidad del marco institucional, cuya nota más prominente ha sido, la persistencia de la Constitución de 1980 y del Sistema Electoral binominal y ii) la profundización de reformas estructurales orientadas a consolidar un sistema centrado en la economía de libre mercado. Por cierto, este es un asunto polémico por cuanto la calificación de los gobiernos de la Concertación debe ser realizada en un contexto en el que desaparecieron coordenadas que permitían construir identidades políticas nítidas y en el que se debía optar entre priorizar democratización o transformación económica. Esta última decisión, constituye para algunos un dilema obligado de suma cero. (Garretón, 2012: 81-85) 
Respecto de la continuidad de las reglas del juego, se observa en el cuadro siguiente (Cuadro 2), la duración de la Constitución de 1980, sus principales reformas desde 1989 y la configuración del sistema de partidos. Se ha agregado una visión de cuatro países; Bolivia, Perú y Uruguay para hacer posible una interpretación de los datos en perspectiva comparada. El primer rasgo a destacar en el caso de Chile, consiste en la vigencia, por más de treinta años, de la Constitución creada por Pinochet, no obstante, consignar reiteradas modificaciones producidas desde 1989. Salvo pocas excepciones (Reformas de 1989 y 2005) el alto número de modificaciones no consiguen atenuar los problemas por legitimidad de origen de este marco normativo. En segundo término, se observa que el rango de fragmentación del sistema de partidos permanece relativamente estable, a nivel de multipartidismo extremo (M.E.), para todo el período desde 1989 a 2012.

Comparado con los otros casos (Bolivia, Perú y Uruguay) se puede sostener que existe relación entre estabilidad en el grado de fragmentación y estabilidad general del sistema político. Para el caso de Perú, el paso de un sistema bipartidista (BIP) a uno multipartidista extremo (M.E.) en 1990 antecede a la regresión autoritaria con Fujimori y para Bolivia, la sucesión de formatos multipartidistas extremos, moderados y extremos coexiste con un debilitamiento de los partidos tradicionales surgidos en la Revolución de 1952, así como de los sistemas de pacto y estrategias coalicionales en uso desde la recuperación de la democracia. El caso de Uruguay, nos previene que aunque importante, el factor fragmentación no puede considerarse causa suficiente de la estabilidad del sistema político, por cuanto los veinte años de multipartidismo moderado (M.M.) (1984-2004) y el surgimiento de una matriz bipartidista (BIP), convivió con un fenómeno de reemplazo entre coaliciones-partidos declinantes y emergentes. Concretamente, se trata del reemplazo de los partidos blanco y colorado en el gobierno por el Frente Amplio EP en el 2005.

Cuadro 2: Continuidades y rupturas constitucionales en cuatro casos 


\begin{tabular}{|c|c|c|c|c|}
\hline & Chile & Bolivia & Perú & Uruguay \\
\hline 1978 & Aut & (CP1967) Aut & Aut & (CP1967) Aut \\
\hline 1980 & (CP1980) Aut & Aut & (CP1979) BIP & Aut \\
\hline 1982 & Aut & Aut & BIP & Aut \\
\hline 1984 & Aut & M.E. & BIP & M.M. \\
\hline 1986 & Aut & M.E. & BIP & M.M. \\
\hline 1988 & Aut & M.E. & $\mathrm{BIP}$ & M.M. \\
\hline 1990 & $\left({ }^{*} 1989\right)$ M.E. & M.M. & M.E. & (*1989) M.M. \\
\hline 1992 & $(* 1991)$ M.E. & M.M. & M.E. & M.M. \\
\hline 1994 & $(* 1994)$ M.E. & $(* 1994)$ M.E. & (CP1993) Aut & $\left({ }^{*} 1994\right)$ M.M. \\
\hline 1996 & M.E. & M.E. & Aut & $\left({ }^{*} 1996\right)$ M.M. \\
\hline 1998 & $(* 1997)$ M.E. & M.E. & Aut & M.M. \\
\hline 2000 & $(* 2000)$ M.E. & M.E. & Aut & M.M. \\
\hline 2002 & $\left({ }^{*} 2001\right)$ M.E. & $\left({ }^{*} 2002\right)$ M.E. & M.E. & M.M. \\
\hline 2004 & $(* 2003)$ M.E. & $(* 2004)$ M.E. & M.E. & (*2004) M.M. \\
\hline 2006 & $(* 2005)$ M.E. & $(* 2005)$ BIP & M.M. & BIP \\
\hline 2008 & M.E. & $\mathrm{BIP}$ & M.M. & BIP \\
\hline 2010 & M.E. & (CP2009) BIP & M.M. & BIP \\
\hline 2012 & M.E. & BIP & M.M. & BIP \\
\hline
\end{tabular}

Fuente: Elaboración propia.

Acerca de la profundización de la sociedad de mercado durante los gobiernos de la Concertación, existen razones para sostener que las cuatro administraciones de esta coalición han contribuido a fortalecer el modelo económico implementado bajo el autoritarismo. Eduardo Lora (2012) ha desarrollado un Índice de Reformas Estructurales con el objetivo de estimar la magnitud de las reformas económicas pro mercado en América Latina. Para este autor, el Índice se compone de cinco variables; política comercial, política financiera, política tributaria, privatizaciones y legislación laboral. A su vez, cada una de estas variables se compone de uno o más indicadores. (Lora, 2012)

Desagregando en perspectiva histórica (1985 a 2009) la variable privatizaciones ${ }^{3}$ obtenemos para el caso de Chile, Bolivia, Perú y Uruguay, el siguiente cuadro con la evolución de la reformas privatizadoras (Cuadro 3). Se observa que Chile avanza de manera constante en este tipo de reformas desde 1985-1986, y continúa a un ritmo semejante durante los gobiernos de la Concertación. Cabe mencionar que para todo el período el índice de privatizaciones en Chile está por encima del promedio de la Región. El caso de Bolivia muestra un aumento más tardío de las privatizaciones y con una tendencia exponencial entre 1994 y 1998, siendo la fase de mayor intensificación de las reformas simultánea a la crisis del sistema de partidos tradicional y la irrupción del MAS. Perú, por su parte, inicia la fase de reformas de manera más tardía, bajo el autoritarismo de Fujimori, para posteriormente, alcanzar los niveles regionales. El caso de Uruguay resulta interesante, porque el país posee los índices más bajos de la región en materia de reformas estructurales y privatizaciones.

\footnotetext{
${ }^{3}$ El índice de privatizaciones se calcula en base al valor de las privatizaciones (acumuladas para medir expansión del sector privado), como porcentaje del PIB. (Lora, 2012: 31)
} 
Cuadro 3: Índice de privatizaciones en cuatro casos

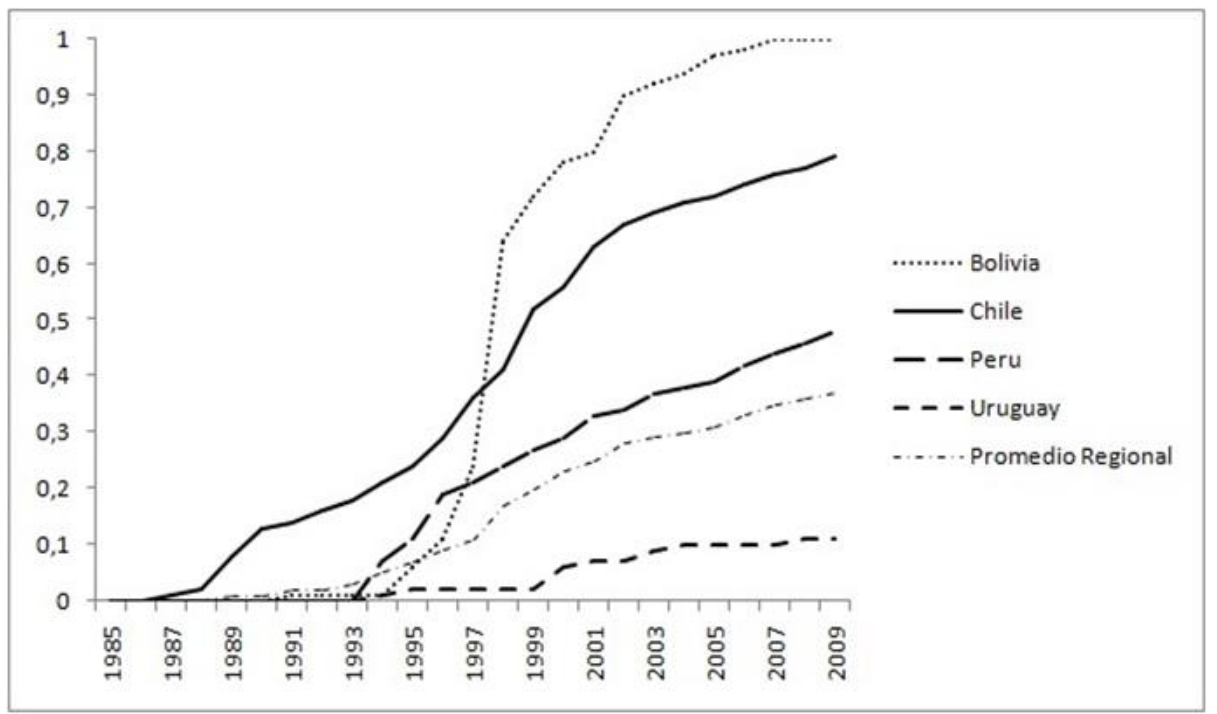

Fuente: elaboración propia en base a datos de Lora (2012).

\section{EXCESO Y DEBILIDAD DE LA VOLUNTAD}

Jon Elster (1988), al fundamentar una reinterpretación del marxismo centrado en el agente (teoría de la acción racional), distingue las preferencias forjadas por las oportunidades (racionalidad adaptativa) de aquellas preferencias forjadas para superar (transgredir) el conjunto de oportunidades disponibles (racionalidad contra-adaptativa). Aunque Elster enfatiza que los alcances últimos de su teoría llegan a la explicación del comportamiento individual de los actores, resulta sugestiva la relación que se puede trazar a nivel de actores colectivos entre racionalidad adaptativa y estrategias de cambio gradual por vía institucional o racionalidad contra-adaptativa y estrategias de cambio rápido por vía de confrontación violenta.

Conceptualmente, la distinción entre "exceso de voluntad" y "debilidad de la voluntad" permite entender el proceso de formación de creencias en los actores y su relación con las decisiones, tal como ocurre con la oposición reformista a Pinochet y, posteriormente, con los cuatro gobiernos concertacionistas. Para Elster, el exceso de voluntad corresponde al intento de conseguir de manera voluntaria aquello que no es posible lograr voluntariamente, dado que se trata de estados que son subproductos $\mathrm{y}$, por tanto, solo son posibles mediante estrategias indirectas. Una variante del exceso de voluntad lo constituye la hiperrracionalidad, esto es, la búsqueda de gran cantidad de información para tomar una decisión. Por su parte, la debilidad de la voluntad consiste en un conflicto de yoes sucesivos, donde predominan las metas de corto plazo frente a las expectativas de beneficios en tiempos medios o largos. Según Elster (1997), la estructura decisional de los actores que poseen debilidad de la voluntad es la siguiente:

Siendo X objetivos de largo plazo, e Y objetivos de corto plazo,

i) Tengo deseo de hacer $\mathrm{X}$ 
ii) Tengo deseo de hacer $Y$

iii) Creo que $\mathrm{X}$ e $\mathrm{Y}$ son incompatible

iv) Creo que debo hacer $X$

v) Hago Y. (Elster, 1997)

En este sentido, la noción de debilidad de la voluntad, hace posible construir una interpretación sobre la propensión adaptativa de la Concertación. Dicha interpretación debería suponer una identificación razonable de factores que condicionan decisiones orientadas a corto plazo cuando (Y), cuando el actor (Concertación) cree que debe actuar orientado a largo plazo $(\mathrm{X})$ y además, $\mathrm{X}$ e $\mathrm{Y}$ son incompatibles.

Observando en perspectiva histórica los procesos de formación de preferencias de los actores políticos chilenos se identifica entre los partidos de izquierda, una inclinación al exceso de voluntad en la década de 1960 hasta 1973 y una tendencia a la debilidad de la voluntad desde 1990 en adelante. Ambos momentos permite diferenciar, grosso modo, la izquierda anterior y posterior al Régimen Autoritario.

Suponemos que la superación de los encuadres doctrinarios históricos de la izquierda chilena y su proceso posterior de renovación, acaecido desde la década de 1980, han tenido tres fundamentos claves: por una parte, la derogación de aquellas tesis políticoestratégicas que contribuyeron al fracaso del gobierno de la Unidad Popular (UP); por otra, la recepción de tradiciones teóricas que permitan adaptaciones estratégicodoctrinarias frente al nuevo contexto; y finalmente, la construcción de una narrativa capaz de movilizar a una mayoría electoral de respaldo. Cada una de estas operaciones permitió invalidar las narrativas dominantes de los partidos de la UP.

La UP fue una coalición política formada en octubre de 1969, bajo la convocatoria del PS y el PC a diversos actores políticos y sociales. Además de los convocantes la coalición fue integrada por el Movimiento de Acción Popular Unitario (MAPU), Acción Popular Independiente (API), el Partido Socialdemócrata, y desde 1971, el Partido Izquierda Radical y la Izquierda Cristiana. Entre los principales factores de cohesión de la alianza se consignan una crítica severa al gobierno democristiano de Eduardo Frei Montalva y en tono más general, un cuestionamiento a las opciones estratégicas y resultados del Frente Popular.

Aunque ya en el Congreso de Unidad del PS en 1957 se habían establecido líneas estratégicas claves (Tesis del Frente de Trabajadores), sería solo hasta después del triunfo aplastante de la DC, en los Congresos de Linares (1966), Chillán (1967) y La Serena (1971), que el socialismo consolidará una orientación leninista. (Walker, 1990: 143) La declaración emanada del XXI Congreso del PS, realizado en Linares en junio de 1966, señalaba: 
"Nuestra estrategia descarta de hecho la vía electoral como método para alcanzar nuestro objetivo de toma del poder. ¿Significa esto abandonar las elecciones y propiciar el abstencionismo por principios? (...) Un partido revolucionario, que realmente es tal, le dará un sentido y un sentido revolucionario a todos sus pasos, a todas sus acciones y tareas que emprenda y utilizará para estos fines todos los medios que permitan movilizar las masas. (...)

Afirmamos que es un dilema falso plantear si debemos ir por la via electoral o la via insurreccional. El partido tiene un objetivo, y para alcanzarlo deberá utilizar los métodos y los medios que la lucha revolucionaria haga necesarios. La insurrección se tendrá que producir cuando la dirección del movimiento popular comprenda que el proceso social, que ella misma ha impulsado, ha llegado a su madurez y se disponga a servir de partera de la revolución". (Arauco, 1966: 35-36)

Joan E. Garcés (2013) identificó en la UP, una coexistencia de narrativas contradictorias destinadas a cristalizar un proceso de cambio revolucionario por distintas vías. Esta contradicción estratégica subyacente consistió en el uso simultáneo de "tácticas indirectas" y "tácticas directas". Como se aprecia esquemáticamente en el cuadro 4, las primeras destinadas a construir un nuevo orden sociopolítico mediante la vía institucional parlamentaria, y las segundas, destinadas a agudizar las tensiones y generar condiciones para el enfrentamiento civil violento.

Cuadro 4: Caminos para la construcción de un nuevo orden sociopolítico 


\begin{tabular}{l|lll} 
Táctica indirecta & Táctica directa & \\
\hline $\begin{array}{l}\text { Incitación a la coexistencia entre } \\
\text { grupos sociales no antagónicos }\end{array}$ & $\begin{array}{l}\text { Agudización de las tensiones entre } \\
\text { grupos sociales no antagónicos }\end{array}$ \\
\hline $\begin{array}{l}\text { Diferenciación a través de la } \\
\text { irradiación-estimulo }\end{array}$ & $\begin{array}{l}\text { Diferenciación a través de la } \\
\text { disuasión-coerción }\end{array}$ & \\
\hline $\begin{array}{l}\text { Reestructuración socioeconómica y } \\
\text { política }\end{array}$ & $\begin{array}{l}\text { Conflicto agudo entre fuerzas } \\
\text { organizadas }\end{array}$ & \\
\hline Nuevo orden sociopolítico & $\begin{array}{l}\text { Guerra o enfrentamiento civil } \\
\text { violento }\end{array}$ & \\
& Nuevo orden sociopolítico & \\
\hline
\end{tabular}

Fuente: Garcés, Joan E. (2013). 50

En palabras de Garcés esta distinción táctica, consignada en el cuadro de manera dicotómica, apareció en el proceso político efectivo, con matices y grados, dentro de la coalición de respaldo a Salvador Allende. Desde mediados de la década de 1960 tendencias internas del PS y otros actores de izquierda (sectores MAPU y el MIR) se desplazaron hacia posiciones de mayor radicalidad, fortaleciendo la táctica directa, lo que implicó reafirmar la vía revolucionaria y la orientación de estos partidos como expresión de vanguardia de clase. Lo anterior, aunque la posición oficial de la coalición de respaldo de Allende fue el uso de la estrategia indirecta.

En este sentido, Joan Garcés sostiene:

"En Chile, durante el gobierno de la Unidad Popular (UP), puede decirse que el ingreso en el período de transición al socialismo era concebido a través de una vía predominantemente indirecta por el Partido Comunista, el Radical, y una gran parte del Socialista y el MAPU. Otros sectores de estos últimos dos partidos y el Movimiento de Izquierda Revolucionaria (MIR) -que no formaba parte del gobierno- entendían, por el contrario, que solo instrumentando una política según las directrices de la táctica directa el socialismo podría abrirse camino en el país. A su vez, desde el punto de vista de las tácticas contrarrevolucionarias también se daba una contraposición semejante. Mientras el Movimiento Patria y Libertad -inspirado en la Falange Española-, el Partido Nacional y el sector Frei de la Democracia Cristiana oponían en mayor o menor grado a la acción de la UP una resistencia conforme a la táctica directa, el sector Tomic de la DC siempre lo hizo dentro de una indirecta". (Garcés, 2013: 50-51)

De maneta tal, si se considera la situación estratégica de la izquierda en la coyuntura de la UP, el MIR, sectores del PS y sectores MAPU, reivindicaron definiciones leninistarevolucionarias, aunque ello no significara su hegemonía invariable dentro del bloque allendista. Por cierto, la narrativa de Allende en términos estratégicos apareció resumida 
en el concepto de "vía chilena al socialismo", noción que emergió en su discurso del 5 de noviembre de 1970, y desde ese momento, en múltiples documentos oficiales. La "vía chilena al socialismo" se constituyó en la definición estratégica y el proyecto político del gobierno de la UP, siendo su propósito fundamental la construcción del socialismo por vía institucional, esto es, mediante los procedimientos electorales en uso y en "democracia, pluralismo y libertad". (Garretón y Moulián, 1983:161) Obviamente, este camino no seguía los métodos ni la trayectoria de los procesos socialistas tradicionales, no requería diseños de partido único, ni estrategias de rupturas violentas con el orden republicano preexistente, ni tampoco suponía un momento dictatorial o autoritario. (Garretón y Moulián, 1983: 162)

Cuadro 5: Actores políticos ubicados por posiciones de poder y estrategias.

\begin{tabular}{l|l|l} 
& Dominante & Latente \\
\hline Directa & $\begin{array}{l}\text { MIR } \\
\text { Partido Socialista (Sectores) }\end{array}$ & \\
MAPU (Sectores) & Izquierda Cristiana \\
& PDC (Sector Frei) \\
& $\begin{array}{l}\text { Patria y Libertad } \\
\text { Partido Nacional }\end{array}$ & \\
\hline Indirecta & $\begin{array}{l}\text { Allende } \\
\text { Partido Radical } \\
\text { Partido Comunista } \\
\text { MAPU (Sectores) } \\
\text { PDC (Sector Tomic) }\end{array}$ & \\
& Partido Socialista (Sectores) \\
\hline
\end{tabular}

Fuente: Garcés, Joan E. (2013) 51

Al no constituir "la vía chilena al socialismo" una perspectiva hegemónica dentro de la UP, ni menos aún, entre los partidos cercanos que no formaban parte de la coalición, el balance de los factores que precipitaron el Golpe de Estado de 1973, podía llegar a ser contradictorio. Luego del Golpe, en octubre de 1973, el Secretario General del Movimiento de Izquierda Revolucionario (MIR), Miguel Enríquez, sentenciaba que la caída de la UP era un hecho, no solo predecible, sino con lecciones claras para la izquierda; no era viable intentar hacer la revolución socialista, manteniendo intactas las instituciones de la democracia burguesa y buscando el "consentimiento de las clases dominantes". Como señala Julio Pinto, paradojalmente, el fracaso de la "vía chilena...", representó para buena fracción de los partidarios de las tácticas directas, la posibilidad de convertir al MIR -bajo la Dictadura- en la vanguardia del proceso revolucionario. (Valdivia, Álvarez y Pinto, 2006: 153-154)

Luis Guastavino, analizó con especial crudeza la distribución de las responsabilidades en el desenlace final del gobierno de la UP y en la caída del régimen democrático de los partidos que cuestionaron desde la izquierda la "vía chilena al socialismo". Particularmente, Guastavino identificó en las aplicaciones dogmáticas y reduccionistas del leninismo, el factor detonante de los errores de aquellos partidos o sectores que impulsaban tácticas directas dominantes. A ese dogmatismo de sectores proclives a la 
UP, se atribuye la carencia de "racionalidad" frente al proceso político, la ausencia de mayor realismo táctico y la incapacidad de evitar el desenlace de enfrentamiento total en 1973.

"Creo que toda la concepción del gobierno de la Unidad Popular y su ejecutoría están invadidas por un vacío histórico, por una batería ideológica marxista-leninista pervertida por el ejercicio rígido, esquemático y dogmatizado que institucionalizó el otrora movimiento comunista internacional, lo cual afecta a toda la izquierda chilena, ya que en ese tiempo el Partido Socialista llegó al paroxismo en tal dirección ideológica (...) El tema del poder total para la clase obrera, la incomprensión real sobre el tema de la democracia y el juego de mayorías y minorías, los reduccionismos clasistas para enfocar cualquier fenómeno y la errónea apreciación sobre el tema de las capas medias, el dogma de la dictadura del proletariado (...) la absolutización del determinismo económico, las confusiones sobre asuntos como la propiedad o la libertad y muchos otros aspectos contribuyeron a enervar la política de la izquierda (...) el peso del marxismo leninismo codificado otorgaba a la Unidad Popular y a su gobierno calidad democrática dudosa en diversas y decisivas materias para el futuro del país (...) Por eso la Unidad Popular no fue capaz de consolidar los logros de 1971 (...) y comenzaron a operar los ejercicios ultraizquierdistas con su espiral desenfrenada de irresponsabilidad y de confrontación”. (Boeninger, 1998: 217)

Para Edgardo Boeninger (1998), la constelación de factores que desencadenaron, secuencialmente, la crisis del sistema político en 1973 fueron: i) radicalización ideológica de los partidos y predominio del "purismo" ideológico, ii) proyectos globales excluyentes, iii) retracción de lógicas cooperativas y de coexistencia en el sistema de partidos, iv) búsqueda de transformaciones radicales sin mayoría político-social, v) uso de movilización social como mecanismo supletorio para generar presión frente a oponentes, y vi) uso de poderes administrativos del Ejecutivo para evitar negociación con actores con capacidad de veto parlamentario. (Boeninger, 1998: 246-251)

En perspectiva histórica, observando las experiencias coalicionales chilenas del Frente Popular, la Unidad Popular y la Concertación, podemos afirmar que los niveles iniciales de respaldo electoral y parlamentario del presidente, inciden en las posibilidades de mantenimiento de las coaliciones gubernamentales. De acuerdo al cuadro 6 y en una escala decreciente, identificamos cuatro escenarios que facilitan el mantenimiento coalicional, a saber:

i) Mayoría en apoyo al presidente $(\mathrm{MaP})$ y mayoría en apoyo diputados $(\mathrm{MaD})$ durante la Concertación (Aylwin y Frei Ruiz-Tagle);

ii) Minoría en apoyo al presidente (MiP) y mayoría en apoyo diputados $(\mathrm{MaD})$, durante la Concertación (Lagos y Bachelet);

iii) Mayoría en apoyo al presidente (MaP) y minoría en apoyo diputados (MiD), durante el Frente Popular; 
iv) Minoría en apoyo al presidente (MiP) y minoría en apoyo diputados (MiD), durante la Unidad Popular.

Cuadro 6: Contingente electoral y parlamentario inicial

\begin{tabular}{|l|l|l|}
\hline Coalición & $\begin{array}{l}\text { \%Votos } \\
\text { Presidente }\end{array}$ & $\begin{array}{l}\text { \% Votos } \\
\text { Diputados }\end{array}$ \\
\hline Frente Popular & Mayoría & Minoría \\
\hline $\begin{array}{l}\text { Unidad } \\
\text { Popular }\end{array}$ & Minoría & Minoría \\
\hline CONC-Aylwin & Mayoría & Mayoría \\
\hline CONC-Frei & Mayoría & Mayoría \\
\hline CONC-Lagos & Minoría & Mayoría \\
\hline $\begin{array}{l}\text { CONC- } \\
\text { Bachelet }\end{array}$ & Minoría & Mayoría \\
\hline
\end{tabular}

Fuente: Elaboración propia.

Ordenando estos cuatro escenarios desde aquellos que tienden a facilitar el mantenimiento de la coalición a aquellos que tienden a precipitar su declinación o caída, resulta la siguiente secuencia: MaP-MaD> MiP-MaD> MaP-MiD> MiP-MiD. Se puede afirmar, a la luz de estos datos, que el desempeño electoral de la UP (a nivel presidencial y parlamentario) fue el más deficiente de las tres principales coaliciones de izquierda desarrolladas en Chile durante el siglo veinte (FP, UP y Concertación) y, en consecuencia, constituyen la constelación más propicia para el fracaso del conglomerado y el colapso del régimen político. Bajo esta constelación de factores, la "difícil combinación” de presidencialismo y multipartidismo (Mainwaring, 1995), demostraría ser más bien una mixtura insostenible.

\section{INTERIORIZACIÓN DEL ANIQUILAMIENTO}

En el proceso político chileno, la oportunidad para la introducción de conceptos iconoclastas dependió, inicialmente, del cambio abrupto en las relaciones de poder con ocasión de la coyuntura de 1973 y de los mecanismos subjetivos de apropiación de dicha experiencia. Desde ese año, se produjeron cambios drásticos en la condición de actores, a la sazón dominantes, que produjeron desplazamientos en las creencias tradicionales y el abandono de las posiciones leninistas y de táctica directa. Estos cambios, estuvieron acompañados de una fuerte percepción de fracaso generacional entre quienes fueron actores relativamente centrales y proclives a la UP.

Eugenio Tironi en su libro "La Torre de Babel" (1984), recuerda que en la izquierda chilena se transitó, en pocos años, desde la condición de sujeto con ideales o preferencias autónomas (frente a las oportunidades), a sujeto sometido por las restricciones impuestas por el contexto histórico. Tironi lo describe del siguiente modo: 
"Nuestra generación corre el riesgo de ser tal vez la más frustrada en lo corrido de este siglo. Las expectativas protagónicas que en un tiempo alcanzó a amasar, y el trauma sistemático que la ha perseguido desde 1973, difícilmente tengan paragón en Chile. Fuimos los dioses desde siempre. En nosotros, aquel sentimiento de omnipotencia que, para bien de la especie, cada cual lleva consigo, fue llevado hasta el límite. En torno suyo se construyó algo así como una cultura de cual fuimos, a la vez, resultado y gestores. Porque la propia historia era para nosotros un avance y un progreso continuos, sin regresiones violentas e irreversibles. (...) Nuestra omnipotencia no parecía encontrar limites sociales infranqueables y no hallaba cómo y en que vertirse positivamente. Se acumulaban, es verdad, muchos fracasos, errores, limitaciones; pero lo cierto era que el carro, después de todo, avanzaba en el sentido que queríamos, aun cuando su marcha nos parecía irritantemente lenta." (Tironi, 1984: 17-19)

Además de la tragedia subjetiva de la izquierda en Chile durante el autoritarismo, Tironi consigna un conjunto de transformaciones estructurales y de larga duración ocurridas después de la Segunda Guerra Mundial en las democracias de mayor desarrollo (Expansión del mercado, complejización de la estructura social, crisis de legitimidad del Estado de Bienestar, entre otros fenómenos). Estos procesos representan al mismo tiempo, condiciones históricas, sociales y culturales que obligar a pensar los desafíos de la izquierda en los años 80 bajo un marco de restricciones objetivas. Al llegar los últimos años de la década de 1980, se observa, según este sociólogo, un nuevo escenario en Chile, fundado en condiciones que requerían el necesario ajuste programático de la izquierda, entre estas:

a) El abandono de la función mediadora del Estado frente a las contradicciones sociales en sistemas capitalistas ha generado una "agudización, intensificación y atomización de los conflictos" así como su desplazamiento al ámbito privado.

b) La disminución del porcentaje obreros en la fuerza total de trabajo, aumento del empleo informal y mantención del porcentaje de desempleados, situación que debilita el "anclaje social" de los partidos de izquierda.

c) El debilitamiento y remisión de valores tradicionales de las culturas de izquierda y expansión de los valores propios de las sociedades centradas en el mercado (individualismo, consumismo y competencia). (Tironi, 1984: 30)

Los desplazamientos ideológicos y estratégicos de actores frente a la retracción de las tradiciones dominantes en el pensamiento de la izquierda chilena tenían concordancia con los modos de reconstruir explicaciones del fracaso político de la UP y los modos de interiorizar la experiencia de la violencia del régimen autoritario. En un primer análisis aparece, hacie finales de la década de 1970, la subversión táctica entre el PS y el PC. Mientras el PC, situado en 1973 en el eje de partidos que asumen tácticas indirectas, se desplazó hacia una estrategia directa de tipo insurreccional; el PS dominado inicialmente por la perspectiva de tácticas directas durante la UP se desplazó hacia una racionalidad "adaptativa". 
Eugenio Tironi argumenta que la principal ruptura "epistemológica" en la izquierda, durante el autoritarismo, consistió en dejar atrás el leninismo que marcó al pensamiento marxista de fines de la década del 1960 y comienzos de 1970. (Tironi, 1984) Junto a ello, se produjo el surgimiento de tradiciones (autores, conceptos) que, con mayor o menor coherencia, posibilitaron la reconstrucción del socialismo en tiempos de crisis del Estado. Tironi llegó a sostener (de manera premonitoria) que en los comienzos de 1980 se observan coincidencias nítidas entre el neoliberalismo y ciertas formas de socialismo libertario. (Tironi, 1984: 41-43) Entre estas coincidencias aparecían los siguientes rasgos: i) la reducción del tamaño y poder del Estado, ii) el valor irreductible del individuo y su libertad, iii) la defensa de la autonomía del mercado respecto de cualquier forma de intervención. (Tironi, 1984: 41-43)

\section{LA FUERZA NORMATIVA DE LO FACTICO}

En esta coyuntura de aniquilamiento, aparecieron dos patrones de importación de ideas destinados a amalgamar el pensamiento socialista con la crisis del Estado y la expansión de la economía de mercado: por una parte, una corriente centrada en la subjetividad, la vida cotidiana y los mecanismos de reproducción social (Lechner, 1986); por otra, aparece una variante centrada en el actor como sujeto dotado de racionalidad elaborada, preferentemente, por el marxismo de la elección racional (Wright,1997).

Norbet Lechner en "Los patios interiores de la democracia" (1988), recordando las contribuciones de Agnes Heller y Norbert Elías para el estudio de la vida cotidiana, sostiene:

"Ella (Agnes Heller) entiende por vida cotidiana el conjunto de actividades que caracterizan la reproducción de los hombres particulares, los cuales, a su vez, crean la posibilidad de la reproducción social. Ella enfatiza así el carácter de mediación que relaciona las prácticas singulares a la producción y reproducción del orden social a la vez que da cuenta de la determinación estructural de las experiencias subjetivas. Cabe concluir (...) que no hay razón para pensar que sean incompatibles la investigación de las estructuras de la convivencia social (que realizada unilateralmente, bien puede ser llamada objetivista) y la investigación del sentido con que los mismos participantes viven los distintos aspectos de su convivencia (que analizado unilateralmente puede ser llamado subjetivista). Sobre todo si consideramos el proceso de cambio social, el estudio de la experiencia (del tipo como los hombres en relación con su vivencia de las estructuras sociales contribuyen a su reproducción, como a su transformación) es tan indispensable como el estudio de los mecanismos de enlace a largo plazo, no planificados y ciegos que obran en el cambio de las estructuras". (Lechner, 1988: 376377) 
De acuerdo a Lechner, los mecanismos de reproducción social permiten comprender el mantenimiento del orden social, incluso en contextos, como el autoritario, donde existen condiciones de violencia individual o estructural que harían suponer oportunidades para el cambio político. Norbert Lechner (1986), afirma que, aunque el fundamento último de la dominación y la conflictividad social tiene un sustrato material evidente (conflicto entre propietarios y no propietarios), los mecanismos que posibilitan mantener el orden, incluso en condiciones materiales desfavorables, surgen (de las implicancias subjetivas) del divorcio entre la "existencia y el proyecto". En este punto, Lechner antepone las condiciones objetivas que garantizan a los sujetos una base mínima de seguridad o la consecución de sus intereses básicos, por sobre la dimensión normativa. Sería, más relevante y anterior, la mantención de una forma de orden, en concordancia con la estructura de intereses creados, que apostar a estrategias destinadas a romper el status quo. Estas ideas, relevan la creencia acerca del "poder normativo de lo fáctico", noción elaborada por Hans Kelsen que designaba la tendencia a conferir rango de normativo a aquello que existe de hecho. (Lechner, 1986)

En palabras de Lechner:

"La relación de poder no surge de un contrato social; ni siquiera aparece como el resultado de una actividad planificada de los usurpadores. La división entre gobernantes y gobernados se establece sin recurrir ni a la violencia ni al consenso. Aparece como un faít accompli; algo tan simple y complejo como un hecho. Lo decisivo es, que a través de este proceso de facto la relación de poder se desarrolla como orden. Es lo que se conoce como el poder normativo de lo fáctico. La determinación fáctica de la realidad es a la vez una determinación normativa. El poderse realiza qua orden. La realidad no es una naturaleza muerta sino una producción social. La realidad se construye (también) a la fuerza y esa fuerza se objetiva en el poder de la realidad. Queremos enfatizar esta fuerza de las cosas. Se trata de una coerción estructural que no suplanta la coacción física directa (siempre presente como ultima ratio); la complementa como una violencia institucionalizada. El poder no es solamente la coacción física; es también y sobre todo el poder de la estructura social. En esa cosificación y rutinización del poder como fuerza de las cosas radica el orden y es en ese orden cotidiano donde se origina el reconocimiento del poder estatal". (Lechner, 1986: 70)

\section{RACIONALIDAD ADAPTATIVA}

Para fines de este trabajo, nos interesa explorar con especial cuidado la vertiente de la renovación socialista centrada en el sujeto en tanto "actor racional", acorde a los supuestos del marxismo de la elección racional. Esta corriente se caracterizó por la elaboración de una noción de sujeto, apoyada en la experiencia del fracaso de la voluntad y la pasión como motor de la decisión de los actores políticos. Como se ha visto en otros trabajos (Mella, 2011) (Paramio, 1986), Jon Elster constituyó, desde el "marxismo analítico" (MA) una expresión fundante de la crítica a la ortodoxia marxista. 
Entendemos que el MA se trata de una tradición crítica fundamentada en una oposición tajante frente al "colectivismo metodológico" de la ortodoxia marxista, por cuanto, sus explicaciones se apoyarían en la "actuación del todo" y no en sus partes constitutivas. Por esta actitud de dogmatismo evidente, la ortodoxia argumenta que las categorías sociales fundantes de la tradición (por ejemplo el Estado, el capitalismo y las relaciones de Clase) son irreductibles a procesos de nivel micro. En Ulises y las Sirenas (1989) Elster denomina a este sesgo dogmático, explicaciones "funcionales", por cuanto subyace en ellas una actitud profundamente ideológica que persigue la defensa de la concepción evolutiva y teleológica vigente en ciertas tradiciones del marxismo burocratizado. $^{4}$

Ángel Flisfisch ha sostenido en "Los ideales y la izquierda: la racionalidad del cambio" (1987), que, históricamente, uno de los rasgos centrales del pensamiento de izquierda ha consistido en un "desajuste o falta de correspondencia" entre los ideales (preferencias) y el estado de cosas existente. (Flisfisch, 1987: 1) O como bien dice Leszek Kolakovski, la izquierda se define, idiosincráticamente, por su "tendencia a modificar las cosas". Si la izquierda se identifica con un pensamiento en el que lo propio es una brecha entre la dimensión aspiracional a nivel subjetivo y el orden actual; entonces, buena parte del desafío para quienes se autoperciben ubicados en esta posición, consiste en imaginar mundos posibles alternativos y condiciones límites. Por condiciones límites, entendemos el horizonte de lo posible, considerando las condiciones dadas por la coyuntura y por las tendencias estructurales.

Sin embargo, lo que usualmente no se advierte es la relación entre la experiencia de fracaso y el impulso adapatativo hacia la estructura de preferencias originales. Flisfisch supone que es más frecuente encontrar casos en los cuales las consideraciones estratégicas modifican preferencias, y no al revés, como se piensa tradicionalmente, casos en los que son los propósitos de la acción los que definen los medios apropiados.

"Desde el punto de vista de la mantención de un status quo, o de la introducción de reajustes marginales en él, discriminar entre lo posible y lo imposible, lo viable o lo inviable, lo eficaz y lo ineficaz, tiende a ser un asunto rutinario. Aquí, el material para hacerse de creencias sobre que es viable y la evidencia que fundamente esas creencias, es un solo mundo posible que se confunde con el mundo realmente existente. Para una política de izquierda, dada la escala de las transformaciones deseadas y perseguidas, ese material comprende otros mundos posibles, distintos del realmente existente, y ello explica tanto arbitrariedad en las creencias sobre lo que es posible, como una naturaleza particularmente tenue de la evidencia que las fundamenta”. (Flisfisch, 1987: 3)

\footnotetext{
${ }^{4}$ Para este punto también puede se puede consultar: Cohen G., "La teoría de la historia de Karl Marx. Una defensa". (1986): 275 a 326.
} 
El mismo autor, agrega que estudios de los partidos socialdemócratas durante las últimas décadas, permiten concluir que la evolución de estos partidos se caracterizó por un predominio de racionalidad instrumental de tipo adaptativo para ajustar la estructura de preferencias a las oportunidades. Más concretamente, ajustar los objetivos políticos a la disponibilidad de respaldo electoral. (Flisfisch, 1987) Con seguridad, el fracaso estratégico más relevante para las izquierdas latinoamericanas durante la segunda mitad del siglo veinte fue la caída de los regímenes democráticos, la declinación electoral combinada con maximalismo ideológico y la proliferación en la región de autoritarismos de cuño militar desde 1964. (Flisfisch, 1987: 6)

Se sostiene, por ende, que la adaptación de los fines a las oportunidades será legítima cuando constituya una expresión autónoma, reflexiva y pública de procesos adaptativos. En este escenario, el giro en las creencias no tendría nada de reprochable. Eso ocurrió en cierto sector de la izquierda opositora a Pinochet, al internalizar la idea de democracia como fin superior de la acción política a partir del "fracaso catastrófico". (Flisfisch, 1987: 9)

Un proceso bastante distinto se habría dado con la creciente tolerancia de la izquierda frente al sistema capitalista. En este plano, se habría tratado de un proceso de acomodación "no consciente" y por tanto, "no intencional" de ideales, siendo realizado dicho proceso "a espaldas" de los actores. Así, el cambio en las preferencias de la izquierda reformista habría sido una expresión de irracionalidad o, parafraseando a Ludolfo Paramio, de "anomia política". (Flisfisch, 1987: 10) En tono más coloquial, otros autores han llamado a esta dinámica de asimilación, "la sopa común neoliberal". (Otano, 1995: 134-147)

Sin embargo, más allá de lo dicho, se producirá la adaptación de la izquierda reformista a la institucionalidad heredada del autoritarismo, engendrándose políticas de profundización del modelo de mercado. José Joaquín Brunner (1983), ha analizado las estrategias de socialización y los contenidos de la "cultura autoritaria" poniendo énfasis en el carácter dicotómico frente al pasado histórico preautoritario. Respecto de dicha socialización, Brunner observa un conjunto de cadenas causales, que contribuyeron a generar un desprestigio extendido del Estado. Sin embargo, no es razonable sostener por ello que la adaptación de sectores de la izquierda al discurso de mercado pudo haber sido a espaldas de la racionalidad de los actores, en la medida que se tiene a la vista los mecanismos electivos instrumentados por los gobiernos de la Concertación.

Edgardo Boeninger señalaba en 1998 que la oportunidad del gobierno de Aylwin para implementar su fórmula de "crecimiento con equidad", fue estrecha e implicó un conjunto de elecciones estratégicas:

"Debemos tener claro que la opción del crecimiento con equidad tiene márgenes de operación estrechas. Una reducción no muy dramática del compromiso con la equidad 
en términos de políticas y programas concretos de gobierno, nos puede hacer caer de hecho en la opción neoliberal. Del mismo modo, ceder a la tentación de acentuar el esfuerzo social mediante un mayor gasto público o de intentar un cambio más drástico de tipo redistributivista, conducen rápida e inevitablemente a la opción populista con el riesgo cierto de ciclos de inflación, desempleo, estancamiento e inestabilidad; es preciso tener claro que no hay plena compatibilidad, al menos en el corto plazo, y en menor medida, en el mediano plazo, entre elevar los niveles de inversión y crecimiento económico y lograr un éxito espectacular en la política de erradicación de la pobreza y de mayor equidad". (Boeninger, 1998: 464 y 465)

Si consideramos lo anterior, no parece ser el único criterio para definir la racionalidad adaptativa en la izquierda, el nivel de consciencia desarrollado por los actores frente al proceso. Un aspecto no estimado suficientemente por Ángel Flisfisch, consiste en el peso de la variable temporal para la realización de preferencias. Sabemos por Jon Elster que la "debilidad de la voluntad" implica el enfrentamiento de yoes sucesivos, donde predominan las preferencias de corto plazo.

Por lo general, las investigaciones de fines de los 80 y comienzos de 1990 distinguían entre las tareas de la transición y los desafíos de la democratización, coincidiendo en que se debía dar prioridad a las primeras. Si se atiende a esta distinción, apreciamos que desde 1990 la Concertación tendió a formular, más bien, las metas de corto o mediano plazo que favorecieran la consolidación democrática, vale decir, la eliminación de amenazas de regresión autoritaria y la continuidad de la coalición en el poder. (Boeninger, 1998: 35) Esta inclinación por el corto plazo que prolongó inercias institucionales y de políticas públicas se puede analizar mediante el estudio de la implementación de las políticas y la composición de ministerios.

Si se analiza, por ejemplo, la producción legislativa para los primeros tres gobiernos de la Concertación, se concluirá que, precisamente, aquellos temas que más inciden en la estabilidad de las reglas del juego son las áreas que poseen un menor nivel de logro. Edgardo Boeninger (2007), al analizar la producción legislativa Concertacionista, desagrega la agenda legislativa en diez temas: 1 . Beneficios a favor de funcionarios públicos, 2. Proyectos económicos y financieros, 3. Proyectos a favor de sectores de la actividad nacional, 4. Reformas sectoriales, 5. Convenios Internacionales, 6. Acuerdos de libre comercio, 7. Cambios político-institucionales, 8. Derechos humanos y asuntos militares, 9. Varios, 10. Leyes de presupuesto. En este contexto, el autor identifica los temas estratégicos para la persistencia del marco institucional, como las reformas sectoriales (con énfasis en reformas mayores), derechos humanos y asuntos militares y cambios político-institucionales, en los cuales se aprecia menor porcentaje de productividad legislativa durante los primeros tres gobiernos. (Boeninger, 2007: 140141) 
Por otra parte, apoyándonos en los estudios de configuraciones de gabinetes en presidencialismo de coalición, podemos sostener, que el carácter técnico de los ministros y su menor dependencia de las estructuras partidarias, en general, facilitan la implementación de reformas de amplio espectro (Amorim Neto y Borsani, 2004). En Chile, el patrón de dependencia desde 1990, caracterizado por reproducir las correlaciones parlamentarias en la distribución de ministerios, se mantuvo constante durante los cuatro gobiernos de la Concertación hasta 2010. Específicamente, el coeficiente de correlación entre la composición del primer gabinete de cada uno de los cuatro gobiernos y la elección inmediatamente anterior arroja valores próximos a 1, lo que significa alta capacidad de reproducción de las correlaciones parlamentarias en la composición de los gabinetes (Aylwin 0,93; Frei 0,99; Lagos 0,99 y Bachelet 0,83). Por tanto, si los partidos de la Concertación durante el período 1990-2010 experimentaron una fuerte propensión adaptativa y fueron altamente influyentes en la composición del poder ejecutivo, es posible sostener (en base al modo de relación del gobierno y su coalición de partidos), que no existieron condiciones propicias para la generación de reformas profundas y de larga implementación.

\section{A MODO DE CONCLUSIÓN}

Para John Pocock, existen dos posibles entradas al estudio del pensamiento político, a saber; analizar los diferentes tipos de relaciones entre los conceptos de una tradición y la tradición misma; y por otra parte, analizar las relaciones entre conceptos de una tradición y la conducta resultante. (Pocock, 2009: 27) En cierto sentido, se supone que el pensamiento político se desarrollaría entre la abstracción pura de los teóricos y el mundo de la acción. Por tanto, nos ha interesado el pensamiento de la renovación socialista y la afluencia del marxismo de la elección racional (analítico) en las creencias de los actores del período, como fórmulas destinadas a equilibrar la experiencia en un mundo asumido como ajeno y la necesidad de actuar, desde una izquierda aniquilada en sus creencias, contra la violencia autoritaria.

Específicamente hemos preguntado ¿Cómo impactaron estos desplazamientos ideológicos a las definiciones estratégicas de la izquierda chilena y, específicamente, a la "renovación socialista"? y a continuación ¿Cuál fue la relación entre las teorías iconoclastas (entre ellas, el "marxismo analítico") y los procesos adaptativos del pensamiento Concertacionista y del Socialismo en particular?

Acerca del primer problema, sostenemos que los desplazamientos ideológicos y las rupturas de la izquierda de estirpe socialista durante el régimen autoritario de Pinochet, así como su intensa adaptación a las preexistencias a nivel institucional y de modelo de desarrollo, se tradujeron desde comienzos de la década de 1990, en dos narrativas que formaron parte del sentido común concertacionista. Por un lado, una narrativa "negativa" tendiente a quitar legitimidad y desestructurar a ciertas creencias dominantes entre aquellos actores "responsables" de la derrota del proyecto de la UP. Este ha sido el caso, por ejemplo, el caso de la crítica o deconstrucción de la "táctica directa" en su 
forma leninista, así como, de diferentes expresiones de ortodoxia. Por otra parte, una narrativa "positiva" tendiente a definir nuevas creencias bajo conceptos iconoclastas, en el contexto de la renovación socialista. Estos han sido los casos de la revalorización de la idea de democracia, el agente, la subjetividad y la racionalidad.

En relación a la segunda pregunta, podemos concluir que las teorías iconoclastas en la izquierda fueron inicialmente objeto de una recepción instrumental para procesar el aniquilamiento y sostener el enfrentamiento contra el régimen autoritario provistos de repertorios adecuados a los tiempos de crisis de la ortodoxia marxista. La posibilidad que la alternativa final para derrotar a Pinochet fuese la vía electoral, también actúo como factor dinamizador de la recepción de estas nuevas ideas heterodoxas en sectores "cosmopolitas" de la izquierda chilena. En momentos posteriores al autoritarismo, durante los cuatro gobiernos de la Concertación (1990 a 2010), la racionalidad adaptativa y la debilidad de la voluntad, originalmente instrumentos funcionales para recuperar la democracia, se convirtieron en creencias fetiches para el nuevo sentido común del socialismo. Dichos referentes idiosincráticos fueron proyectados en el tiempo por un desempeño electoral sobresaliente del conglomerado.

Así, la "debilidad de la voluntad" se transformó, progresivamente, en defensa del status quo o profundización del modelo heredado, todo ello "convirtiendo la necesidad en virtud". La fuerte propensión adaptativa de la Concertación hizo posible, que en las narrativas del socialismo se impusieran creencias heréticas, mudando la cultura de la izquierda, en mayor o menor medida, a partir del "poder normativo de lo fáctico".

\section{BIBLIOGRAFIA}

AMORIM NETO, O. y BORSANI, H. (2004). "Presidents and Cabinets: The Political Determinants of Fiscal Behavior in Latin America". Studies in Comparative International Development 39 (1): 3-27.

BOENINGER, E. (1998), Democracia en Chile. Lecciones para la gobernabilidad, Santiago, Andrés Bello.

(2007), Políticas Públicas en Democracia. Institutcionalidad y experiencia chilena 1990-2006). Santiago: UQBAR-CIEPLAN.

BRUNNER, J.J. (1983) Entrevistas, Discursos, Identidades. Santiago: FLACSO.

COHEN, G. (1984), "Réplica a Marxismo, funcionalismo y teoría de juegos de Elster", en Zona Abierta, $N^{\circ}$ 33, Madrid, Fundación Pablo Iglesias.

(1986) La teoría de la historia de Karl Marx. Una defensa. Siglo XXI-Pablo Iglesias. Madrid. 
DEZALAY, Y., y GARTH, B. (2002), La internacionalización de las luchas por el poder. La competencia entre abogados y economistas por transformar los estados latinoamericanos, Bogotá / ILSA, Universidad Nacional de Colombia / Facultad de Derecho / Ciencias Políticas y Sociales.

ELSTER, J. (1984), "Marxismo, funcionalismo y teoría de juegos. Alegato en favor del individualismo metodológico", en Zona Abierta, núm. 33, Madrid, Fundación Pablo Iglesias.

(1988), Uvas Amargas. Sobre la subversión de la racionalidad, Barcelona, Ediciones 62.

(1989) Ulises y las sirenas, México, Fondo de Cultura Económica.

(1997) Egonómics, Barcelona, Gedisa.

(2003), Tuercas y tornillos, Barcelona, Gedisa.

FLISFISCH, Á. (1982), "Modelos de recepción de identidades políticas”, en Material de Discusión, núm. 31, Chile, FLACSO.

(1983), "Coaliciones políticas y transición en Chile: notas exploratorias", en Material de Discusión, núm. 45, Chile, FLACSO.

(1984), "Hacia un realismo político distinto" en Documento de Trabajo, núm. 219, Chile, FLACSO.

--------- (1987), "Los ideales y la izquierda: la racionalidad del cambio", en Documento de Trabajo, núm. 355, Chile, FLACSO.

GARCÉS, E. JOAN (2013). Allende y la Experiencia Chilena. Las armas de la política. Santiago: Siglo XXI-Hueders.

GARRETON, M.A. Y MOULIAN, T. (1983) La Unidad Popular y el conflicto político en Chile. Santiago: Ediciones Minga.

HELD, D. (1991) Modelos de Democracia. Madrid: Alianza.

LEVINE, A., SOBER, E., y WRIGHT, E.O. (1987). Marxismo e individualismo metodológico. Zona Abierta, ISSN 0210-2692, N 41-42, págs. 131-158.

LECHNER, N. (1986), La conflictiva y nunca acabada construcción del orden deseado, Madrid, Siglo XXI. En LECHNER, N. (2006) Obras escogidas 1. Colección pensadores latinoamericanos. Santiago: LOM. (1988), Los patios interiores de la democracia, Santiago, FLACSO.

LORA, E. (2012) Las reformas estructurales en América Latina: Qué se ha reformado y cómo medirlo (Versión actualizada). Washington DC: Banco Interamericano de Desarrollo (BID). Documento de trabajo del BID \# IDB-WP-346. Consultado el 02 de septiembre de 2013: http://www.iadb.org/intal/intalcdi/PE/2012/10450.pdf 
MAINWARING, S. (1995): «Presidencialismo, multipartidismo y democracia: la difícil combinación», Revista Española de Estudios Políticos, № 88.

MELLA, M. (2011a). Referentes internacionales para el giro reformista de la izquierda chilena (1975-1990). Revista Espacios Públicos ISSN 1665-8140 01/2011; Año 14(No. 30):155-175.

(2010). El eclecticismo no resuelto del liderazgo de Ricardo Lagos. DAAPGE ISSN 1851-3727 09/2010; año 10(No 14):113-142.

(2011b). El pensamiento sobre la modernización y la democratización durante el gobierno de Eduardo Frei Ruiz-Tagle. Revista de Estudios Politécnicos Tékhne, Instituto Politéctico do Cávado e do Ave. ISSN: 1645-9911 01/2011; vol. IX(No 15,): 105-132$.

(2008). Los intelectuales de los Centros Académicos Independientes y el surgimiento del Concertacionismo. Revista de Historia Social y de las Mentalidades ISSN: 0717-5248 01/2008; Volumen 1(Número 12):83-121.

MOYANO, C. (2011). Diálogos entre el exilio y el interior. Reflexiones en torno a la circulación de ideas en el proceso de renovación socialista, 1973-1990. Revista Izquierdas, $\mathrm{N}^{\circ}$ 9, 31-46.

OFFE, C. (1989). Contradicciones de la democracia capitalista. Revista Convergencia. $\mathrm{N}^{\circ}$ 15, Santiago: 53-59.

OTANO, R. (1995) Crónica de la Transición. Santiago: Planeta.

PARAMIO, L. (1986), "Tras el diluvio: introducción al Post-Marxismo", en Contribuciones, núm. 45, Chile, FLACSO.

POCOCK, J.G.A.(2009) Pensamiento político e historia. Ensayos sobre teoría y método. Madrid: Akal.

PRZEWORSKI, A. (1988) Capitalismo y socialdemocracia, Madrid, Alianza.

SANTONI, A. (2013) Modelos y antimodelos de la Renovación Socialista. La Revista Convergencia y la crisis del socialismo mundial (1981-1991). Historia 46: I, enerojunio, 153-176.

SEPÚlVEDA, A. (1988) Problemas del Partido Socialista de Chile posteriores al Golpe Militar. 1974-1981. México D.F. (Mimeo)

TIRONI, E. (1984). La Torre de Babel. Ensayos de Crítica y Renovación Política. Ediciones SUR, Colección Estudios Sociales. 
VALDIVIA, V., ÁlVAREZ, R. y PINTO, J. (2006). Su revolución contra nuestra revolución. Izquierdas y derechas en el Chile de Pinochet (1973-1981). Santiago: LOM.

WRIGHT, E.O. (1997) Reflexiones sobre socialismo, capitalismo y marxismo. Palma de Mallorca: Secretaría de Estudios y Programas. Confederación Sindical de Comisiones Obreras (CCOO). Colección Contextos.

Recibido: 25 marzo 2015 Aceptado: 30 mayo 2015 